\title{
Mothers' Knowledge on the Effects of Malnutrition in Children 0-5 Years in Muea Health Area Cameroon
}

\author{
Samuel Nambile Cumber ${ }^{1,2, *}$, Nkengateh Babara Ankraleh², Nina Monju ${ }^{2}$ \\ ${ }^{1}$ Discipline of Public Health Medicine, Department of Nursing \& Public Health, College of Health Sciences, University of Kwazulu-Natal \\ Durban, South Africa \\ ${ }^{2}$ Under Privilege Children and Women Assistance (UPCAWA-SWEDEN), Buea, Cameroon
}

Email address:

samuelcumber@yahoo.com (S. N. Cumber)

*Corresponding author

\section{To cite this article:}

Samuel Nambile Cumber, Nkengateh Babara Ankraleh, Nina Monju. Mothers' Knowledge on the Effects of Malnutrition in Children 0-5 Years in Muea Health Area Cameroon. Journal of Family Medicine and Health Care. Vol. 2, No. 4, 2016, pp. 36-42. doi: $10.11648 /$ j.jfmhc.20160204.13

Received: October 1, 2016; Accepted: October 9, 2016; Published: November 2, 2016

\begin{abstract}
Malnutrition is a condition that develops when the body does not get the required foods nutrients in their rights proportions. Malnutrition is also as a result of underfeeding or overfeeding. Increase nutritional needs such as vitamins, minerals, protein supplements in children can help reduce further complication. This study was carried out in Muea -Sub Divisional Medical Centre, South West Region of Cameroon. This study involves a sample population of 30 mothers who were recruited through a convenient sampling technique and data was collected through the administration of questionnaire to respondents (mothers) which was designed with respect to the objectives of the study which were in four sections based on their on the causes and effects of malnutrition in children 0-5 years. Most of the mothers were of aged 2130 years, the result obtained shows that $73 \%$ of mothers had knowledge on malnutrition, $50 \%$ had knowledge on the effect of malnutrition in children while $50 \%$ of mothers had insufficient knowledge on the effect of malnutrition in children. Their knowledge increases with the number of children and level of education. It was concluded that most mothers with one, two or more children had knowledge on the causes and effects of malnutrition in children. Through health talk emphasize should be laid on the causes and effects of malnutrition in children during ANC and IWC especially to women with low level of education.
\end{abstract}

Keywords: Mothers: Knowledge, Malnutrition, Children, Cameroon

\section{Introduction}

Malnutrition is a condition that develops when the body does not get the require food nutrients in their right proportions. Such food nutrients include vitamins, minerals, proteins, carbohydrate and fat and lipids it needs to maintain healthy tissues and organ functions. [1, 2] Malnutrition can also occur when an individual's diet does not provide him/her with adequate calories and proteins needed for maintenance and growth or they cannot fully utilize the food they eat due to illness (under nutrition), while those who suffer from over nutrition consumes too much calories. [1, 3, 4] During neonatal development, there are some nutritional needs such as high needs for some vitamins and minerals, and children are advised to follow up their daily food plan for months to meet most of these increased needs for important nutrients like folic acid and iron. [5]

Living organisms especially human beings need nutrients gotten from the food we eat to live and function healthy. [1, 3-5] Therefore any deviation from the normal can affect the quantity (number) and quality can cause a problem to the life we live. Good nutrition ensures good life and also effectiveness of one's life. [2, 4] Malnutrition can also result to further complications during pregnancy and after birth to both mother and child such as low birth weight, low immunity, diseases such as anaemia, and during neonatal development. Children should increase intake of vitamin and mineral supplements. [1-3] Consumption of drinks like alcohol by pregnant women should be avoided because it can pose harm to the fetus during development. [5, 6]

There are two major types of malnutrition namely; Protein- 
energy malnutrition resulting from deficiencies of any or all nutrients and micronutrients malnutrition resulting from deficiency in vitamins and minerals. [5]

There are three types of protein- energy malnutrition in children described as follows:

i. Acute malnutrition is wasting or thinness, acute inadequate nutrients leading to rapid weight loss or failure to gain weight normally.

ii. Chronic malnutrition refers to shortness caused by inadequate nutrition over a long period of time leading to failure in linear growth.

iii. Wasting and stunting are very different forms of malnutrition. Stunting is chronic and its causative factors are poorly understood. Stunting usually does not pose an immediate threat to life and is relatively common in many populations in the less developed countries.

Some signs and symptoms may include weight loss, breathing difficulties, higher susceptibility to cold and other diseases, higher risk of hypothermia. Severely malnourished children typically experience slow behavioral development; even mental retardation may occur. [6, 7]

Malnutrition is when the body does not get the require foods nutrients in their right proportions. [1-3] Such food nutrients include vitamins, minerals, protein. Carbohydrates, fats and lipids needs to maintain healthy tissues and organ function. [1, 8] Good nutrition early in life is a key input for human capital formation, the fundamental for sustainable and equitable economic growth. Any major deviation in the intake either the quality or quantity form these requirements can affect growth in many ways. [5, 8, 9] Child under nutrition is the leading cause of burden of disease. $[5,10]$ Many women do not prepare their children a balanced meal may be due to lack of knowledge or financial problems. [4, 7] Lack of good nutritional requirements lead to poor growth of the child, poor intellectual reasoning, frequent infections and consequently dead. $[9,10]$

During the author's volunteer services at Muea SubMedical Centre at the pediatric unit realized that many children especially 0-5 years were not looking healthy. Therefore I did some inquiries from their mothers on how they prepare their children food and realized that they do not have adequate knowledge on balanced diet. Thus there is a need for this study so as to assess mothers' knowledge on the effects of malnutrition in children $0-5$ years so that their children will grow healthily and physically strong to reproduce their healthy offspring and the family will leave in peace and harmony.

Some research questions where: To assess mother's knowledge on the effects of malnutrition in children 0-5 years old in the Muea community.

- To assess mothers knowledge on nutrition.

- To verify if the mothers are aware of the causes of malnutrition in their children (0-5years).

- To assess mothers knowledge on the effects of malnutrition on their children (0-5years).

- To verify if the mothers are aware of the management and prevention of malnutrition in their children ( $0-5$ years).
Malnutrition is preventable and this cannot be achieved by the health workers only. So, the study is going to assist in creating a partnership between health workers and mothers to work towards identifying, treating and preventing malnutrition.

The study involves mothers with children 0-5 years living in Muea community at the time of study. (July 2015 to march 2016) attending IWC in Muea Sub-Divisional Medical Centre.

Some of the limitations of the study where; Language barrier was equally another problem since majority of the respondents could understand Pidgin English better compared to English language. This alone was highly stressful as the researcher needed to take her time to explain and interpret the questions to their understanding. Some respondents expressed a hostile behavior towards the researcher they think that she wanted to exploit them. This was because it was probably, their first time to take part in such an exercise as they expressed verbally.

\section{Material and Methods}

\subsection{Description of Study Area}

The study area being the Muea Sub-divisional Medical Center is located in Muea situated in Buea, Fako division which is found in the South West Region. The Muea Subdivisional Medical Center is located opposite Presbyterian Church Muea and equally beside the government primary school. Muea Sub-divisional Medical Center is estimated to serve a population of about 20809 people a year. The Muea Sub-divisional Medical Center is headed by a director and is made up of thirty six staff; one director, three doctors, one general supervisor four majors, sixteen nursing assistance, two pharmacy attendants, three laboratory technicians, two revenue collectors, two wards mates, one yard man and one security man (Information gotten from the General Supervisor of Muea Sub-Divisional Medical Centre).

Muea has a moderate economy with agriculture, administration, business and financial sectors taking the central stage, agriculture is the main occupation of the people. The hospital is situated a few $\mathrm{km}$ away from the main road and adjacent to the Presbyterian Church area (chief of Muea July 2015).

\subsection{Study Population}

The target population for this study was some of the mothers who were of age 21 to 40 and above and who were presently residing in Muea at the time of study.

\subsection{Research Design}

A cross sectional descriptive study design was the design that was best suited for this study.

\subsection{Sample Size}

This research was carried out using 30 mothers in Muea community with specific criteria as below. 


\subsubsection{Inclusive Criteria}

Some individuals in the Muea community that were mothers at the time of the research who were willing to let go a piece of their time to take part of the research and could answer questions feely without being ashamed.

\subsubsection{Exclusive Criteria}

Some mothers who were not present and those mothers who refused to be part of the exercise.

\subsection{Sampling Technique / Research Materials}

The sampling technique for the study was a convenient a sampling technique whereby the research had to meet most of the mothers during their visits on days scheduled for IWC. The researcher made use of pencils, pens, papers, and questionnaires in order to collect the data for this research.

\subsection{Study Period}

The research program lasted for the period of 9 months that is from July 2015 to March 2016 and the researcher managed to collect all required samples within one week.

\subsection{Method of Data Collection}

A semi-structural questionnaire composed of opened and close-ended was used to collect data. On this questionnaire, there was a short instruction addressed to the respondents, informing them on how to answer the questions. Below, the questionnaire was partitioned into five sections with section A that need information on the demographic status of the respondents, and the other three sections that required answers on questions posed regarding the four specific objectives. The researcher finally printed 30 copies of the questionnaires expecting to have 30 questionnaires well filled.

\subsection{Method of Data Analysis}

Data generated from the study was entered in a Microsoft excel page. It was then transferred to a satisfied software program (MINYAB15.0) for analysis. The data was analyzed using tables, pie charts and histograms.

\subsection{Reliability and Validation of Questionnaire}

After establishing the questionnaires, a copy was summated to the supervisor of the work who did some necessary corrections. 10 copies were administered to the mothers at the saint Veronica's clinic during their IWC for pre-testing to test its eligibility. With the test being positive, 30 copies were then printed and become eligible for study.

\subsection{Ethical Consideration Administrative Permission}

Permission for the research exercise was granted by the Director of Muea Sub Divisional Medical Centre. Letter was obtained from Saint Francis Higher Institute of Nursing and Midwifery Bokoko-Buea with hand writing application. Another ethical clearance form was obtained from the regional delegation of public health in Buea. The participants equally granted verbal concern before the questionnaire; strict confidentiality was assured as the respondents were not to disclose their identity by any means whatsoever.

\section{Results}

\subsection{Demography}

The study recruited 30 mothers, majority $63 \%$ of whom were of age between $21-30$ years, $7 \%$ were aged $>40$ years and also majority of $53 \%$ were married. Base on their religion, majority of $50 \%$ were catholic and also $57 \%$ were farmers and $47 \%$ of these mothers had two children and also, $40 \%$ were holder of FSLC and the following are represented on the table below as follows.

Table 1. Distribution of Demography Data.

\begin{tabular}{|c|c|c|c|c|}
\hline $\mathbf{S} / \mathbf{N}$ & Parameters & Range(years) & Frequency (F) & Percentages (\%) \\
\hline \multirow{4}{*}{1} & \multirow{4}{*}{ Age } & 21 & 4 & $13 \%$ \\
\hline & & $21-30$ & 19 & $63 \%$ \\
\hline & & $30-40$ & 5 & $17 \%$ \\
\hline & & $>40$ & 2 & $7 \%$ \\
\hline \multirow[t]{4}{*}{2} & Marital & Married & 16 & $53 \%$ \\
\hline & & Divorce & 3 & $10 \%$ \\
\hline & & Single & 9 & $30 \%$ \\
\hline & & widow & 2 & $7 \%$ \\
\hline \multirow[t]{3}{*}{3} & Religion & Catholic & 15 & $50 \%$ \\
\hline & & Muslim & 2 & $7 \%$ \\
\hline & & Orthodos & 0 & $0 \%$ \\
\hline \multirow{3}{*}{4} & \multirow{3}{*}{ Profession } & Others & 13 & $43 \%$ \\
\hline & & Teacher & 4 & $13 \%$ \\
\hline & & Farmer & 17 & $57 \%$ \\
\hline \multirow{5}{*}{5} & \multirow{5}{*}{$\begin{array}{l}\text { Number of } \\
\text { children }\end{array}$} & House wife & 6 & $20 \%$ \\
\hline & & Others & 3 & $10 \%$ \\
\hline & & one child & 7 & $23 \%$ \\
\hline & & Two children & 14 & $47 \%$ \\
\hline & & Three children & 4 & $13 \%$ \\
\hline \multirow{5}{*}{6} & \multirow{5}{*}{$\begin{array}{l}\text { Educational } \\
\text { level }\end{array}$} & $>4$ children & 5 & $17 \%$ \\
\hline & & FSLC & 12 & $40 \%$ \\
\hline & & Ordinary level & 9 & $30 \%$ \\
\hline & & Advance Level & 5 & $17 \%$ \\
\hline & & Others & 4 & $13 \%$ \\
\hline
\end{tabular}

\subsection{Knowledge}

\subsubsection{Identification of Mother's Knowledge on Malnutrition in Children}

Participant with $73 \%$ indicated that malnutrition is when the child started having large head and swollen stomach, having weight loss and having proper body nutritional requirements while I participant with $3 \%$ identify children who are always crying of hunger as definition of malnutrition in children as seen on table 2 below. 
Table 2. Distribution of mother's knowledge on malnutrition.

\begin{tabular}{llll}
\hline S/N & Definitions & frequency (F) & Percentage (\%) \\
\hline A & $\begin{array}{l}\text { children having proper baby } \\
\text { nutritional requirements(nutrient) } \\
\text { children who are always crying } \\
\text { of hunger } \\
\text { children having large head and }\end{array}$ & 5 & $17 \%$ \\
Bwollen stomach, having weight \\
C & $\begin{array}{l}\text { loss and having proper body } \\
\text { nutritional requirement }\end{array}$ & $3 \%$ \\
D & $\begin{array}{l}\text { I don't know } \\
\text { TOTAL }\end{array}$ & 2 & $73 \%$ \\
\hline
\end{tabular}

\subsubsection{Mothers Knowledge on the Causes of Malnutrition}

A majority of the respondents $(30,50 \%)$ indicated that malnutrition is cause by poor hygienic condition in preparing the child's food, poverty, unsafe water, diseases and infections. $20 \%$ said that it is cause when the child is exclusively breastfed for the first 6 months seen on table 3 below.

Table 3. Distribution of Mothers knowledge on the causes of malnutrition.

\begin{tabular}{llll}
\hline S/N & Causes & frequency & percentage \\
\hline A & $\begin{array}{l}\text { when the child is exclusively } \\
\text { breastfed for the first 6 months } \\
\text { poor hygienic condition in preparing } \\
\text { the child food, poverty, unsafe water, }\end{array}$ & 6 & $20 \%$ \\
B & 15 & $50 \%$ \\
diseases, and infections & 6 & $20 \%$ \\
D & $\begin{array}{l}\text { I don't know } \\
\text { when the child is eating too much }\end{array}$ & 3 & $10 \%$ \\
& TOTAL & 30 & $100 \%$ \\
\hline
\end{tabular}

\subsubsection{Mothers Knowledge on Signs and Symptoms of Malnutrition}

$40 \%$ of the participant identify skin may become thin, dry, inelastic, longer time for recovery from infection and illness as signs and symptoms of malnutrition in children, 6months with $20 \%$ identify vomiting as the sign and symptoms of malnutrition in children as seen on fig 1 below.

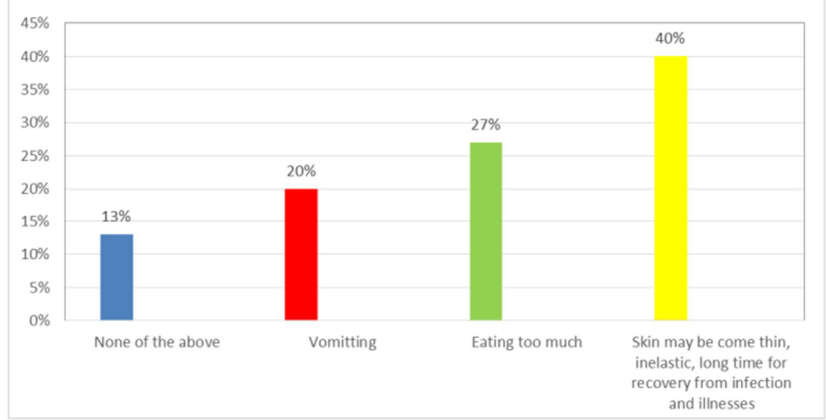

Fig. 1. Distribution of mothers' knowledge of the signs and symptoms of malnutrition.

Identification of mother's knowledge on the effects of malnutrition in children $0-5$ years

\subsubsection{Knowledge on the Effects to a Child}

15 mothers with $50 \%$ identify the child body immunity will not be well build up, it may also lead to anemia and death while $20 \%$ of the participants had no idea on the on the effects of malnutrition to a child and $27 \%$ identify that the child will be crying as the effect of child malnutrition as shown on fig 2 below.

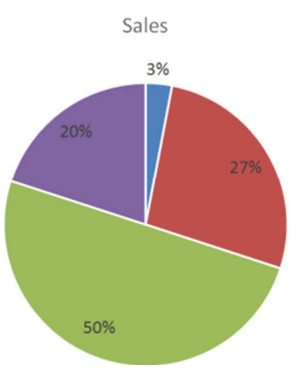

$$
\begin{aligned}
& \text { - The child will be strong } \\
& \text { - The child will be Crying } \\
& \text { - The child body imunity will not be well build up, it may lead to anemia and death } \\
& \text { - I don't know }
\end{aligned}
$$

Fig. 2. Distribution of effects of malnutrition on the child.

Iidentification of mother's knowledge on the prevention of malnutrition in children

\subsection{Prevention Knowledge}

\subsubsection{Mothers Knowledge on Prevention of Malnutrition in Their Children}

A majority of the respondents $(30,67 \%)$ indicated that feeding the child with food that contains all classes of nutrients will help prevent malnutrition. $10 \%$ said that by feeding the child every two hours will help prevent malnutrition as seen on fig 3 below.

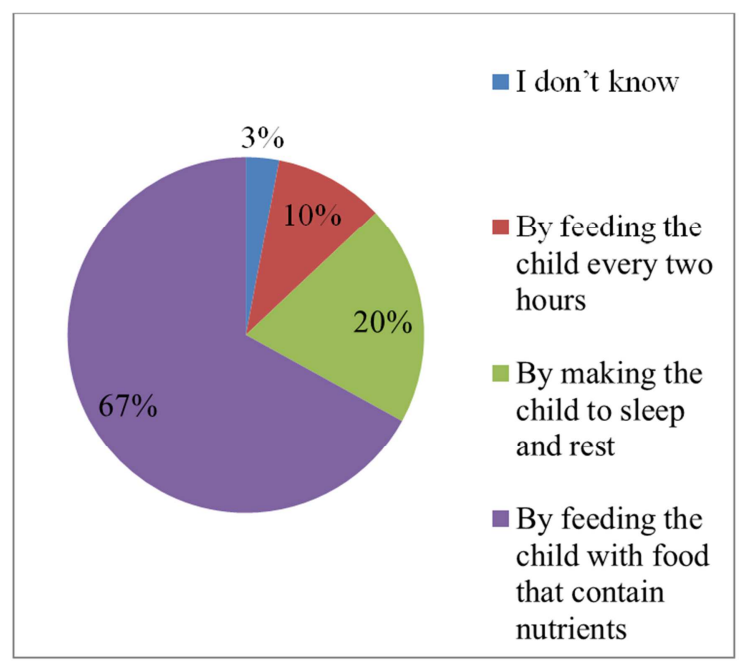

Fig. 3. Distribution of mother's knowledge on the prevention of malnutrition in children.

\subsubsection{Mothers Knowledge on a Good Diet Necessary for the Prevention of Malnutrition}

A majority of the participant $(30,40 \%)$ indicated that rice and stew with fish or liver is good diet necessary to prevent malnutrition. 30\% said Exclusive breastfeeding from 0-6 months is a good diet to prevent malnutrition as shown on fig 4 below. 


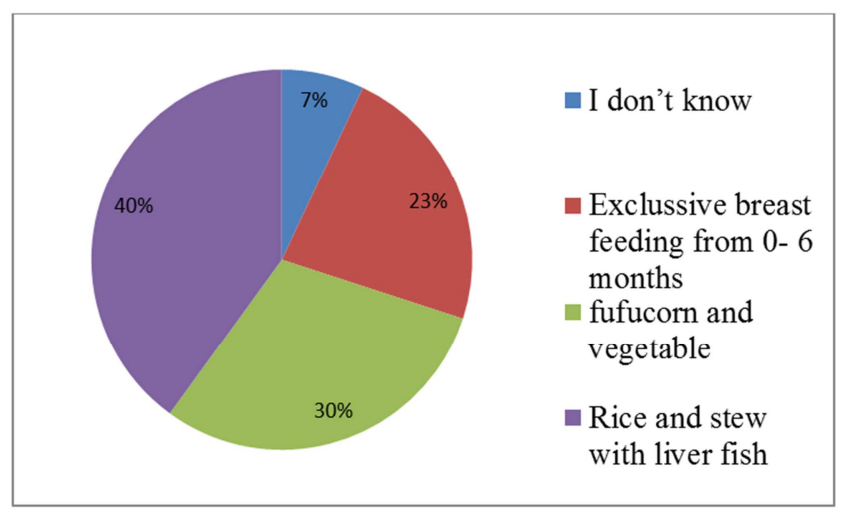

Fig. 4. Distribution of mother's knowledge on a good diet necessary for the prevention of malnutrition.

\section{Discussion}

\subsection{Mothers Knowledge on Malnutrition in Children 0-5 Years}

Majority of 22 mothers with a percentage of $73 \%$ on table 2 said malnutrition during child hood is when the child is having large head and swollen stomach, having weight loss and not having proper body nutritional requirements. This is line with Anderson and William, who define malnutrition in children as a condition that develops when the body does not get the right proportions of food nutrients during child hood. $[1,2]$ Base on the data analysis on the causes of malnutrition in children, 15 mothers with majority percentage of $50 \%$ said child's malnutrition is as a result of poor hygienic condition is preparing the child's food, poverty, unsafe water diseases and infections.

This is in line with WHO, that says diseases, poor hygienic condition, and poverty unsafe water can lead to malnutrition in children. [5] On the definitive signs and symptoms of malnutrition, 12 mothers with majority of $40 \%$ said signs and symptoms of malnutrition in children include, skin may become this, inelastic, longer time for recovery from infection and illness. [11-13] This is in line with WEHAB, who said, inadequate food intake or consumption of nonnutritious food will lead to reduce muscle mass. [11]

\subsection{Mothers Knowledge on the Effects of Malnutrition in Children 0-5 Years}

15 mothers with $50 \%$ on fig 2 said malnutrition in children will lead to a reduction in the body immunity may also lead to anemia and death. This is in line with the work of de Sandige et al., who says a malnourished child is likely to have low weight susceptible to disease and premature death. [9]

\subsection{Mothers Knowledge on the Prevention of Malnutrition in Children 0-5 Years}

On the prevention of malnutrition, majority of $67 \%$ (that is 20) mothers in number said child's malnutrition can be prevented by feeding the child with food that contains all classes of nutrients. Also, 12 mothers with a percentage of
$40 \%$ being the majority said that exclusive breastfeeding from o- 6 months can prevent malnutrition in children.

This is in line with UNICEF, (2006) who says a good nutrition is the cornerstone for survival, health and development for current succeeding generations and wellnourished children perform better in school, grow in to healthy state in life. [5]

\section{Conclusion}

Base on the fact that malnutrition is the insufficient, excessive or imbalance consumptions of nutrients or results from over feeding or under feeding, it was necessary to carry out this study to assess mother's knowledge on the effects of malnutrition in children 0-5 years. From the data analyzed, it can be concluded that;

- Majority of the study population understand the causes of malnutrition in children $0-5$ years.

- Majority of the mothers did not understand the signs and symptoms of malnutrition in children 0-5 years.

- Prevention of malnutrition in children is well known by the mothers.

\section{Recommendation}

As majority of the mothers attends their ANC and IWC at the Buea health District, more emphases should be laid on health talks with effects of malnutrition in children $0-5$ years being the top priority so as to enable the mothers to know more about the effects, causes, signs and symptoms and the prevention of malnutrition in their children.

Outreach campaign programmers should be organized constantly in order to educate the mother more on the effects and prevention of malnutrition in children 0-5 years. Also emphasis should be laid to mother on exclusive breast feeding from 0-6 months of a child since breast milk contain all the nutrients that a child need in order to grow healthy.

\section{Appendix 1}

Operational Definition of Terms

1. Nutrition: it is the science that deals with the study of food, its composition and its utilization by the human body.

2. Food: it is any substance which when consumed, is broken down to release nutrients for the proper functioning of the body.

3. Nutrients: These are chemical substances present is food that when consumed in their right proportion will nourish the body.

4. Meal: It is the composition of several food items carefully prepared for consumption with adequate nutrient proportions that will provide for basic functioning of the body.

5. The diet: It is a composition of nutrients present in food in their right proportions and eaten at a right time to provide nourishment for the body.

6. A balance diet: It is a diet that contains all he nutrients 
in their right proportions according to the recommended dietary allowance (RDA).

\section{Appendix 2: Questionnaire}

Section A: Demographic Data

1. Your age in years:
A.21years
B. 21-30
C. $30-40$
D. $>40$

2. Marital status:
A. married
B. divorce
C. Single
D. Widow

3. Religion:

A. Catholic

B. Muslim

C. Orthodox

D. others.

4. Profession:
A. Teacher
B. Farmer
C. House wife
D. Others

5. Number of Children:
A. One
B. Two
C. Three
D. $\geq 4$

6. Level of education:
A. First school leaving certificates
B. Ordinary level
C. Advance level
D. others

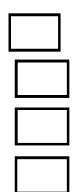

Section B: Mothers knowledge on Malnutrition in Children 0-5 years.

1. What is malnutrition in Children?

A. Children having proper body nutritional requirements (nutrients)

B. Children who are always crying of hunger

C. Having large head and swollen stomach, having weight loss and not prepare body nutritional requirement.

D. I don't know

2. What causes malnutrition in children $0-5$ years?

A. When the child is breastfed for the first months
B. Poor hygienic condition is preparing the child's food, poverty unsafe water diseases infections.

C. I don't know

D. When the child is eating too much.

3. What are the signs and symptoms of malnutrition?

A. Eating too much

B. vomiting

C. skin may be come thin, dry, inelastic, local time for recovery from infection and illness

D. No of the above

Section C: Mothers Knowledge on the Effects of Malnutrition in Children (0-5years)

1. What will happen to a child if he/she is malnourished?

A. The child will be strong

B. The child will be crying

C. The child body's immunity will not be well built up, it may also lead to anemia and death

D. I don't know

Section D: Mothers Knowledge on Prevention of Malnutrition in Their Children 0-5 years

1. How do mothers prevent malnutrition in their children?

2. A good diet or meal necessary for the prevention of malnutrition includes;

\section{References}

[1] Anderson AS, Anil Ray (2012). Pregnancy as a time for dietary change? proc Nutrition Soc2011;60:497-504.

[2] William Blake (2004) "malnutrition a cause for concern in Africa and the world at large" Minache printing house. New Jerssy. USA. p. 4-7.

[3] Hossain M, Massan MQ, Rahman MH, Kabir AR, (2009). Hospital Management of Severely Malnourished Children: Comparison of Locally Adapted Protocol with WHO Protocol. Ind. Pediatr, 46: 213-7. (PubMed). http://www.ncbi.nlm.nih.gov/pub medhealth/PM0001441/.

[4] Henri Josserand, Kisan Gunjal and Ali Gürkan, Ricardo Sibrian (ESS); and Andrew Marx, Jeff Marzilli, Josef Schmidhuber and Jakob Skoet (ESA). The State of Food Insecurity in the World 2008" Food and Agriculture Organization (FAO). Accessed September 20th 2016.

[5] World Health organization (2006). WHO child growth standards, length/height- for age, weight- for-age, and weight -for length, weight -for height and body mass index- for -age.methods and development. WHO multicenter Growth Reference study group. Geneva: WHO (312 pages).

[6] New NICE guideline will help tackle the problem of malnutrition in the NHS'The National Institute for Health and Clinical Excellence (NICE) and the National Collaborating Centre for Acute Care. Accessed September 20th 2016. 
[7] Nkou A., Sumbele L. Markah EN, Njunda A.L Samje M, and kanga L. (2008) "malaria and malnutrition in rural village in Cameroon (Muea) retrieved at http://www. Cameroon -todaywith- malnutrition- and malaria- ynti/writs/1982/2008- $\mathrm{x}$ $\mathrm{htm} /$ accessed on the $17^{\text {th }}$ of August 2015 .

[8] Caulfield LE, de Onis M, Blossener M, Black RE (2004). Under nutrition as an underlying cause of child deaths associated with diarrhea, pneumonia, malaria and measles. American journal of clinical Nutrition; 80: 193-98.

[9] Sandige H, Ndekha MJ, Briend A, Ashorn P, Manary MJ, (2004). Home- based treatment of malnourished Malawian children with locally produced or imported ready-to-use food. J. Pediatri. Gastroenterol Nutr. 39:141-6 (PubMed).
[10] Nutrition support in adults: Oral Nutrition Support, Enterable Tube Feeding and Parenteral Nutrition; NICE (2006).

[11] WEHAB (2002). A framework for action on health and the environment. World summit on sustainable development, Johannesburg, South Africa.

[12] Unicef (2006) the prevalence of stunting among children under 2 years "The larcef inc 8067-70 Geneva. P.14.

[13] Manary MJ, Sandige HL (2008). Management of Acute Moderate and Severe childhood Malnutrition. BMJ. Nov 13; 337: a2180. Doi: 10. 1136/ bmj.a2180. 